\title{
Celebrating the 120th anniversary of the School of Pharmaceutical Sciences of the University of São Paulo
}

\author{
Profa. Primavera Borelli
}

Director of School of Pharmaceutical Sciences

The Faculdade de Ciências Farmacêuticas da Universidade de São Paulo (School of Pharmaceutical Sciences of the University of São Paulo) has recently completed 120 years. It began with the community of pharmacists of what was the Province of São Paulo, defending their professional rights in a society in continuous expansion owing to immigration, with significant growth of the urban sector and industrialization both in the capital of the State and in the countryside. This demand was already brought to attention by Dr. Cesário Motta and bound to the statutes of the Sociedade Pharmaceutica Paulista (São Paulo Pharmaceutical Society). On October $12^{\text {th }}$ of 1898 , in the capital of the province of São Paulo, Braulio Gomes gave a speech in the inauguration of the Escola Livre de Pharmacia, in the Municipal Council session room, at Rua do Thezouro n. 2. ${ }^{1,2}$

The Escola Livre de Pharmacia was the first educational institution devoted to the health sciences and the third college in São Paulo. In 1902, the Bachelor Course in Dentistry was created at the School which, at the time, was already responsible for granting licenses to midwives. In 1903, the School was authorized to create these programs, renaming itself to Escola de Farmácia, Odontologia e obstetrícia de São Paulo. From 1912 on, the course of Obstetrics was discontinued and the school was renamed to Escola de Farmácia e Odontologia, and finally, in 1924, Faculdade de Farmácia e Odontologia (School of Pharmacy and Dentistry). In 1934 the School was merged to the University of São Paulo, becoming one of its founding institutions. ${ }^{3}$ In 1963 Pharmacy and Dentistry were separated in School of Dentistry and School of Pharmacy and Biochemistry. This denomination last until 1970, when it received its current name: School of Pharmaceutical Sciences, as a reflection of the broad scope of the activities of the pharmaceutical profession.

From its inception to the current days, the School of Pharmaceutical Sciences remains stable and driven towards the generation of knowledge to advance in the most diverse areas of Pharmaceutical Sciences. It became a reference in both undergraduate and graduate levels, enabling qualified human resources with inquisitive view, able to work in all relevant fields in pharmaceutical sciences.

Along its 120 years of existence, the School of Pharmaceutical Sciences pioneered undergraduate education by implementing the Farmácia Escola (School Pharmacy, first in the state of São Paulo) and the Laboratory of Clinical and Toxicological Analysis. It has also participated of the creation and implementation of the Pharmacy Division and the Clinic Laboratory at University Hospital of the University of São Paulo, created the Bioequivalence Service, and the Laboratory for Controlling Medicines, Cosmetics, Household cleaning items, Similar Products and their Raw Materials (CONFAR), important services when generic medications were implemented in Brazil. Those activities, asides from providing support to undergraduate level education, also provide extension services for the community. Recently, in 2012, the School of Pharmaceutical Sciences created the first Residence Program in Clinical Pharmacy of São Paulo and the new model of School Pharmacy including pharmaceutical clinic.

Regarding graduate level education, the School of Pharmaceutical Sciences pioneered with the creation of the following graduate programs: Food Sciences, starting its activities in 1968 and accredited in 1970, and the Toxicological and Clinical Analysis program, in 1972, the first in Brazil. Currently, it holds five graduate programs: Physiopathology and Toxicology, Food Sciences, Drugs and Medicines, Biochemical-Pharmaceutical Technology, Toxicology and Toxicological Analysis. These programs allow graduate students to receive solid knowledge allied to theoretical and technological advances. These programs have been important training centers for researches, originating novel research groups in practically all regions of Brazil. The School maintains relations with other research and educational institutions, public and private, 
national and foreign, allowing constant interchange of ideas and technology.

Regarding university extension, the School of Pharmaceutical Sciences was also pioneer: in 1965 it created the Semana Paulista de Farmácia (Paulista Week for Pharmacy), and the Jornada Científica (Scientific Symposium); the School of Pharmaceutical Sciences was also part of Projeto Rondon and, later, USP's advanced Campus in Marabá; it holds the first junior company in the pharmacy sector in Brazil (FarmaJr).

Throughout its 120 years, professors and alumni from the School of Pharmaceutical Sciences have been taking important positions in the pharmaceutical, food and cosmetics industry, in Brazil and abroad - where they occupy leadership positions and set trends. They actively contribute to educational and research institutions, both public and private, and to research incentive agencies. Another highlight is their contributions to governmental agencies, in all entities of the Federation, aiding the development and implementation of public policies, such as: the creation of the Fundação para o Remédio Popular (Foundation for low-cost medicine) (FURP), the creation of the Brazilian Food Composition Table (TBCA), and the participation in the Social Network for Alternative Methods to Animal Experimentation (RENAMA).

The School of Pharmaceutical Sciences also pioneered on the creation of journals with the Revista Brasileira de Ciências Farmacêuticas in 1939, which after continuous editorial changes assumed the current name Brazilian Journal of Pharmaceutical Science, recognized as one of the main Brazilian review in the pharmaceutical field. On this special issue, celebrating the 120 years of the School, Prof. Carlota Rangel Yagui, one of the journal editors, organized a review on frontier themes belonging to the Pharmaceutical Sciences such as drug discovery and design for multi-target disease, Drug discovery for neglected diseases and for the Zika virus, natural products drug space, Pharmaceutical and Analytical Quality by Design (QbD), biological drugs and pharmacogenomics. Clearly, the School of Pharmaceutical Sciences is pivotal for pharmaceutical education among similar institutions in the country. Nonetheless, new challenges have appeared: multi- and interdisciplinary focus, the new guideline for the national curriculum, and, along with then, the central role of the pharmaceutical professional regarding the interaction between medication and patient. Regarding public health, one have also to consider its role as transforming agent, preserving scientific and technological innovation. The Faculty has also the challenge of reshaping its graduate programs aiming towards the optimization of infrastructure and the integration of human resources on both staff and faculty. The School of Pharmaceutical Sciences, according to the goals of the University of São Paulo regarding education, research and extension, must broaden its efforts for the knowledge produced here to be shared with the whole of society.

\section{REFERENCES}

1. Act of creation of the Escola Livre de Pharmacia, Revista de Farmácia. São Paulo, 1898;4(8):139-141.

2.Act of presentation of the guidelines and curriculum of the Escola Livre de Pharmacia, Revista de Farmácia. São Paulo, 1898;4(8):141-42.

3. Decree no. 6.283 of Jan, 25th, 1934. 